\title{
Determinants of Barriers to Knowledge Sharing in the Jordanian Hospitality Industry
}

\author{
Nayel Al Hawamdeh ${ }^{1} \&$ Malek Al-edenat ${ }^{1}$ \\ ${ }^{1}$ Faculty of Business, Business Administration Department, Tafila Technical University, At-Tafila, Jordan \\ Correspondence: Nayel Al Hawamdeh, Faculty of Business, Tafila Technical University, AT-Tafila, P.O.Box179, \\ Tafila, 66110, Jordan.
}

Received: May 22, 2019

Accepted: June 17, 2019

Online Published: June 24, 2019

doi:10.5539/ibr.v12n7p121

URL: https://doi.org/10.5539/ibr.v12n7p121

\begin{abstract}
As well as to examine the differences in attitude of respondents in regard to their demographic characteristic, the purpose of this research is to identify the main barriers to Knowledge Sharing (KS) within the Jordanian hospitality industry; a quantitative approach has been adopted in order to achieve these research objectives, the data being collected via the questionnaire. The sample of this research consisted of 273 managers and employees within ten top hotels in Jordan and the researcher implemented the Statistical Analysis Package (SPSS) so as to analyse the data, the descriptive statistics, mathematical averages, and standard deviations being used to identify the main barriers of KS within the Jordanian hospitality industry. The T-test and One-way ANOVA test were additionally used to examine the hypotheses, the study showcasing that individual and organisational barriers were the main barriers to KS within the Jordanian hospitality industry; meanwhile, technology and knowledge nature were not considered as barriers to KS. The results additionally indicated that there were no statistically significant differences between the responses of the sample members at the level of $\alpha \leq 0.05$ on the barriers to sharing knowledge from the employees at hospitality industry attributed to the following variables: gender; job; age; years of experiences; qualifications.
\end{abstract}

Keywords: barriers to knowledge sharing, knowledge management, knowledge sharing, hospitality industry

\section{Introduction}

Intense competition is currently being faced by service organisations - particularly the hospitality industry-, such organisations focusing on how to enhance their long-term relationships with their customers in order to retain them and attract new customers; according to Hu, Horng,and Sun (2009), Knowledge Sharing (KS) is being increasingly considered to be the most optimal approach when it comes to meeting this challenge within the hospitality industry. A main organisation type within the hospitality industry is that of Jordanian hotels, which are amongst the country's best organisations when it comes to tapping into Knowledge Management, recognising the significance behind KS within daily practices (Dinçer \& Alrawadieh, 2017).

Notably, KS has become a critical aspect of knowledge management within traditional organisations (as well as virtual organisations), and so KS is even more significant than other factors regarding how they impact competitive advantages within new organisations, turning them from classical face-to-face relationships to virtual relationships (Chumg, Cooke, Fry, \& Hung,2015).

Despite the significance of KS within organisations, considering the fact that employees are still not participating to a satisfactory degree in the process of $\mathrm{KS}$ - as well as the fact that there are many barriers to KS within organisations-, it continues to be a problem for a number of them (Ford, Myrden, \& Jones, 2015).

Coupled with its developing nature, Jordan's service-oriented economy signifies an excellent research environment for exploring the phenomenon of KS barriers; most studies of this nature have been undergone within developed countries, resulting in a lack of research conducted within the context of developing countries (e.g., Jordan). Because of this, this study is expected to contribute to knowledge management literature and, particularly that concerning the Jordanian context considering there is an urgent need for more research to be conducted within such a country (Al Hawamdeh ,2018; Al Hawamdeh \& Hackney,2018).

Some significant gaps have been pinpoitned after reflection of the KS-related Literature Review, this identification being considered as a motivation to conduct more empirical research in order to achieve a firmer 
grasp on KS barriers in the specific context of the Jordanian hospitality industry. The current study, thus, attempts to identify the main barriers to KS within Jordanian hotels.

\section{Literature Review}

\subsection{Knowledge Management (KM)}

Representing a critical asset within organisations in today's economy, knowledge is acknowledged to be one of the most important resources within organisations (Nonaka \& Toyama 2005); saying this, one of the most widely adopted perspectives to knowledge management is that of considering it as a process. KM focuses on knowledge flows, linking the process of knowledge to creation, sharing, and the wider breadth and depth of distributing knowledge (Alavi \& Leidner, 2001).

According to currently existing literature concerning Knowledge Management (KM), knowledge is composed of both tacit and explicit knowledge (explained in more depth below), these two dimensions relying on the nature of knowledge; this classification of knowledge has been deemed as the most common within KM literature thus far (Alavi \& Leidner, 2001; Hawryszkiewycz, 2009). The latter form of knowledge can be expressed via any language, writing, or means of communication, and is frequently found in books, documents, and databases (Goh, 2002); it is additionally tangible, visible, formalised, and structured, and can be easily shared/transferred between individuals and organisations (Nonaka, Toyama, \& Konno, 2000). Meanwhile, the former is extremely personal and difficult to formalise, residing in the human mind and being rooted in actions, routines, and experience more than in words (Nonaka et al., 2000); it is additionally difficult to define and codify, and is contextual and sticky (Davenport \& Prusak, 1998; Busch, 2008), only able to be transferred/shared via experience/social interactions (Nonaka, 1994; Hau, Kim, Lee, \& Kim, 2013), considering knowledge consists of habits and behaviours that we do not always notice (Kim, Suh, \& Jun,2011). Individuals often try to hoard tacit knowledge due to the fact that, to them, it is valuable and significant (Yang \& Farn, 2009).

In order to ensure the objectives and goals of the organisation are achieved in the long term, the main role of KM centres on maintaining and retaining the body of knowledge (Wiig, 1997); further, one of the most widely adopted perspectives of KM considers it to be a process, explaining that its focus is on knowledge flows, linking the processes of knowledge to creation, sharing, and, on the wider breadth, to the depth of knowledge distribution (Swan, Newell, Scarbrough, \& Hislop, 1999; Alavi \& Leidner, 2001).

De Long \& Fahey (2000) suggested that knowledge exists within an organisation at three different levels: individual, group, and organisational level; saying this, the most important level for KS and creation is that of the individual level. This is due to the fact that it is recognised as connecting the chain between other knowledge levels, as well as possessing a significant impact on the overall process of knowledge creation (Ipe, 2003).

\subsection{Knowledge Sharing (KS)}

Knowledge Sharing (KS) is recognised to be a knowledge management dilemma; saying this, there are two approaches based on the management of KS within organisations due to the nature of the KS processes, which is very complex: the engineering approach - focusing on how management leads $\mathrm{KS}$-, and the emergent approach - focusing on social nature (van den Hooff \& Huysman, 2009).

Furthermore, according to Ipe (2003), knowledge itself can be divided into two types - organisational knowledge and individual knowledge- - and so the main purpose of knowledge management is to turn employee knowledge into organisational knowledge (Chow \& Chan, 2008); saying this, considering it can help the firm to enhance performance via the transferring of knowledge between employees, thus creating new knowledge, KS is considered as one of the most critical processes amongst the knowledge management processes (Zhang, de Pablos, \& Xu, 2014). Notably, due to the fact that it comprises of a set of behaviours and that knowledge is embedded within the human mind, KS is a very complex process (Chow \& Chan, 2008), as well as a huge concept, incorporating the sharing of both tacit and explicit knowledge at an individual, group, and organisational level.

Thus, KS is a major component of knowledge management (Small \& Sage 2006), and it has received amassed attention from researchers and practitioners in the context of it being a tool for enhancing organisations' innovative performance (Calantone,Cavusgil,\&Zhao,2002). Further, it is also recognised as an important factor of employee performance.

KS can be defined as "the communication of all types of knowledge, which includes explicit knowledge or information, the "knowhow" and "know-who", which are types of knowledge that can be documented and captured as information, and tacit knowledge in the form of skills and competencies' (Al-Hawamdeh, 2003, p. 81 ), whilst KS within a virtual context is more difficult owing to the dependence placed on information 
communication technology (Staples \& Webster, 2008).

As a way to pinpoint the possible shortcomings within the extant literature, a systematic literature review has been undergone; saying this, this paper seeks to contribute to KS literature by providing a review of barriers to KS within the hospitality industry.

Polanyi states, 'I shall reconsider human knowledge by starting from the fact that we can know more than we can tell' (Polanyi, 2009: 4); we have come to realise through these words that the biggest problem with knowledge management is that of the sharing of tacit knowledge. Saying this, tacit and explicit knowledge are not separate from one another, but are complementary, whereby explicit knowledge is linked with know-that, whilst tacit knowledge is linked with know-how; moreover, whilst explicit knowledge is knowledge that can be codified tacit knowledge, tacit knowledge is very difficult to communicate to others via words and symbols (Nonaka, 1994). However, tacit and explicit knowledge are very important to the theory of organisational knowledge creation and to KS as a whole. Notably, within the SECI model, which is composed of four different stages of knowledge conversion (socialisation, externalisation, combination, and internalisation), the interaction and conversion of tacit and explicit knowledge is detailed. On this note, socialisation focuses on the convertion of tacit knowledge to tacit knowledge, whilst externalisation is concerned with the convertion of tacit knowledge to explicit knowledge; combination focuses on the convertion of explicit knowledge to explicit knowledge, and internalisation focuses on the convertion of explicit knowledge to tacit knowledge (Nonaka \& Takeuchi, 1995). $\mathrm{KS}$ is one of the most compound processes within the organisation - especially between individuals within an organisation-, and it is wholly dependent on the relationship between the individuals (Ipe, 2003), the facilitation of KS being a vital element in increasing productivity (Pan et al., 2015). Notably, there are various KS barriers within organisations, which can be divided into three groups: the organisation group, the individual group, and the technological group (Riege, 2005).

\subsection{Knowledge Sharing Barriers}

The impact of KS within organisations is highly complex, this difficulty stemming from a number of causes, i.e., the construct of KS, which consists of a group of factors impacting KS as well as one another (Yang \& Wu, 2008).

Wang and Noe (2010) conducted a systematic review of KS, in the process identifying five areas of KS research: the organisational context, the interpersonal and team characteristics, the cultural characteristics, the individual characteristics, and the motivational factors; further, prior research has suggested that numerous factors affect KS. Saying this, a number of authors have focused on the organisational culture as the significant factor impacting KS (e.g., Kim \& Lee, 2006; Lin, 2008; Seba \& Rowley, 2010; Seba, Rowley,\& Delbridge,2012), whilst others have focused on the national culture (e.g., Wei, Stankosky, Calabrese, \& Lu ,2008; Kivrak, Arslan, Tuncan, \& Birgonul ,2014) and the organisational structure (e.g., Kim \& Lee, 2006; Al-Alawi, Al-Marzooqi, \& Mohammed,2007; Chen \& Huang, 2007; Lin, 2008; Seba et al., 2012) as significant factors. Despite this, other studies have discussed the organisational climate (e.g., Taylor \& Wright, 2004; Chen \& Huang, 2007; Amayah, 2013), such studies being concerned with the impact of social capital dimensions on KS (e.g., Chow \& Chan, 2008; Hau et al., 2013). Additionally, there are researchers who have centred their analyses on the influence of top management support (e.g., Lin, 2007; Fey \& Furu, 2008).

Various studies grounded on KS literature have focused on the factors impacting KS behaviours, such as that of Lin (2007), who identified the three main factors affecting KS: organisational factors, individual factors, and technology factors; further, some authors have suggested that there are three main groups of factors that foster KS within an organisation: the organisational, the individual, and the knowledge levels (Yang \& Wu, 2008).

Ipe (2003) identified four main factors affecting KS individuals within organisations, these factors additionally influencing one another due to them all being interconnected:

1. Knowledge nature: There are two types of knowledge: tacit knowledge and explicit knowledge; saying this, individuals face a number of problems when sharing tacit or explicit knowledge. However, when sharing tacit knowledge, such problems are clearer due to the nature of tacit knowledge. Further, because of that fact that when individuals realise the value of such knowledge they tend to hoard it, the value of knowledge is crucial for KS.

2. Motivation to share: Individuals, by nature, are not likely to share their knowledge without robust motivation to do, and so from this, there are two types of motivation for sharing knowledge at an individual level: 
- Internal motivation factors (e.g., considering knowledge to be power and reciprocity between individuals);

- External motivation factors (e.g., relationships with recipients and the rewards for sharing).

3. Opportunities to share: There are two channels for sharing knowledge: formal instruction and informal instruction; saying this, knowledge that is shared using the formal channel is usually explicit knowledge, whilst tacit knowledge is usually shared via an informal channel.

4. Culture of the work environment: The organisational culture is considered to be the most significant factor impacting KS at the individual level; further, by defining the type of knowledge to share and how it should be shared, the organisational culture impacts KS, the organisational culture also being known to impact the social interactions between the individuals within the organisation.

KS literature has revealed that, as a process, KS faces many barriers that prevent the dissemination of knowledge; indeed, some studies have argued that there are four sets of barriers known to inhibit KS or transferring: the nature of the knowledge, the nature of the sender, the nature of the recipient, and the nature of the context in which the knowledge takes place (Szulanski, 1996); furthermore, Hendriks (1999) suggested that the barriers to KS can be categorised into three main barriers: temporal distance, physical distance, and social distance, whilst Szulanski (1996) argues that there are three major factors posing a barrier to KS: the weakness of the recipient's ability to absorb knowledge, casual ambiguity concerning the knowledge itself, and a difficult relationship between the knowledge sender and the knowledge recipient.

Despite this, Disterer (2001) argues that there are two sources of KS barriers within organisations: individual barriers, and social barriers, whilst on the other hand, Riege (2005) claims that KS practices occasionally fail to obtain their objective during the delivering of the right knowledge from the right sender to the right recipient at the right time due to the three main groups of barriers: organisational barriers, individual barriers, and technology barriers (the majority of which coming from individual barriers). Many of the barriers are not separate from one another, instead being predominately interlinked with other barriers (Kukko, 2013).

\section{Research Questions and Hypotheses}

This research strives to answer the following research questions in light of the literature review discussed above:

- RQ1: What are the main barriers of KS within the Jordanian hospitality industry?

- RQ2: Are there statistically significant differences between the responses of the sample members at the level of $\alpha \leq 0.05$ concerning the barriers of sharing knowledge from the employees at hospitality industry attributed to the variables gender, job, age, years of experience, and qualifications?

To answer this question, the following hypotheses were formulated:

- H1: There are no statistically significant differences between the responses of the sample members at the level of $\alpha \leq 0.05$ on the barriers to sharing knowledge from the employees within the hospitality industry attributed to the gender variable.

- H2: There are no statistically significant differences between the responses of the sample members at the level of $\alpha \leq 0.05$ on the barriers to sharing knowledge from the employees within the hospitality industry attributed to the job variable.

- H3: There are no statistically significant differences between the responses of the sample members at the level of $\alpha \leq 0.05$ on the barriers to sharing knowledge from the employees within the hospitality industry attributed to the age.

- H4: There are no statistically significant differences between the responses of the sample members at the level of $\alpha \leq 0.05$ on the barriers to sharing knowledge from the employees within the hospitality industry attributed to the years of experience variable.

- H5: There are no statistically significant differences between the responses of the sample members at the level of $\alpha \leq 0.05$ on the barriers to sharing knowledge from the employees within the hospitality industry attributed to the qualifications variable.

\section{Methodology}

\subsection{Study Design}

In order to achieve the objective of this research, the quantitative research design has been selected for implementation, as well as the descriptive analytical method; Creswell \& Creswell (2017) have pinpointed the 
fact that the nature of the research question is the most important determinant when selecting which method should be adopted within the given research. Since the objective of the current study is to identify the main barriers to Knowledge Sharing (KS) within the Jordanian hospitality industry; the quantitative approach, thus, has been deemed to be the most suitable.

\subsection{Questionnaire Design}

Considering it provides an efficient means of collecting responses from a large sample before quantitative analysis, questionnaires are very commonly used as a data collection method for descriptive or explanatory research (Saunders, Lewis, \& Thornhill, 2009). As shown in Table 1, based on a review of KS literature, we developed research questionnaires comprising of four groups for barriers; this questionnaire was presented to five experts to evaluate and consider their comments before implementing it, and a 22 -item questionnaire with a five-point Likert-type scale was used to collect data (1 signifying 'strongly disagree', 5 signifying 'strongly agree').

Table 1. The Source of Measurement Items

\begin{tabular}{lll}
\hline Variable & Items & Reference \\
\hline Individual & 8 & Riege, 2005, Seba et al. (2012), Sandhu, M., Jain, K., \& Ahmad, I. (2011), \\
& & Bloice \& Burnett, 2016, Razmerita, Kirchner, \& Nielsen,(2016). \\
Organisational & 7 & Riege (2005); Sandhu et al. (2011); Kukko (2013), Amayah (2013). \\
Information Technology & 3 & Riege (2005); Lin (2007); Seba et al. (2012); Sandhu et al. (2011). \\
Knowledge Nature & 3 & Ipe (2003); Wang (2015). \\
\hline
\end{tabular}

\subsection{Data Collection Procedures}

The target population of the survey was managers and employees from the top 10 hotels within Jordan; after the top management approved within each hotel of their participation within this research, 350 questionnaires were distributed to hotels in Amman, Human Resources (HR) managers also being asked to spread the questionnaires to their employees and to collect them after completion; questionnaires were distributed to the manager and employees within each hotel as the convenience sampling method for selecting hotels was implemented, and so data analysis was based on a sample of 273 valid questionnaires. The response rate was $78 \%$ (as shown in Table 2), and the data was analysed via SPSS, including descriptive analysis, T-test, and one way (ANOVA) .

Table 2. Profiles of Respondents

\begin{tabular}{lll}
\hline Demographic characteristics & Number of responses & Percentage \\
\hline Gender: & 210 & $77 \%$ \\
Male & 63 & $23 \%$ \\
Female & & $29 \%$ \\
Age: & 79 & $38 \%$ \\
$20-29$ & 104 & $33 \%$ \\
$30-39$ & 90 & $35 \%$ \\
40 and Up & & $43 \%$ \\
Work experience: & 95 & $22 \%$ \\
5 years & 118 & \\
$5-9$ years & 60 & $15 \%$ \\
10+ years & & $85 \%$ \\
Job titles: & 41 & $12 \%$ \\
Manager & 232 & $77 \%$ \\
Employee & 33 & $11 \%$ \\
Education level: & 310 & \\
Secondary School+ & 30 & \\
Undergraduate & & \\
Postgraduate & & \\
\hline 5. Results & & \\
\hline
\end{tabular}

\section{Results}

We implemented SPSS (Version 25) to analyse research data, Table 3 showing barriers to sharing knowledge item means and standard deviations.

Table 3. Descriptive Statistics (KS Barriers Categories)

\begin{tabular}{llll}
\hline Category & Mean & SD & Cronbach's Alpha \\
\hline Individual & 2.37 & 0.73 & 0.83 \\
Organisational & 4.33 & 0.25 & 0.72 \\
Technology & 3 & 1.03 & 0.77 \\
Knowledge nature & 2.38 & 0.88 & 0.84 \\
Total & 3.03 & 0.53 & 0.86 \\
\hline
\end{tabular}


Responses will be based on a Likert scale of around 1-5 points, the magnitude of the interval additionally being determined as follows: Maximum score - Minimum score / Maximum score: (5-1)/5=0.8, as shown in Table 4.

Table 4. Respondents Interval Answers

\begin{tabular}{llll}
\hline Range & Interpretation & Range & Interpretation \\
\hline $1-1.8$ & Very low & $3.41-4.20$ & High \\
$1.81-2.60$ & low & $4.21-5$ & Very high \\
$2.61-3.40$ & Average & & \\
\hline
\end{tabular}

To answer the first research question, the mean and the standard deviation of the responses to the questionnaire were calculated as shown within the following tables.

Table 5. Individual Barriers

\begin{tabular}{|c|c|c|c|c|}
\hline & Question & Mean & SD & Degree \\
\hline 1 & Lack of time during the work inhibit Knowledge Sharing in organisation. & 4.6923 & 0.91184 & Very high \\
\hline 2 & $\begin{array}{c}\text { Lack of awareness amongst employees about the value of their knowledge to others } \\
\text { inhibit Knowledge Sharing in organisation. }\end{array}$ & 3.2088 & 1.24425 & Average \\
\hline 3 & $\begin{array}{l}\text { Lack of confidence to participate in KS activities inhibit Knowledge Sharing in } \\
\text { organisation. }\end{array}$ & 4.0220 & 1.21853 & High \\
\hline 4 & Lack of trust between employees inhibit Knowledge Sharing in organisation. & 3.5751 & 0.97903 & High \\
\hline 5 & $\begin{array}{l}\text { Large differences in experiences levels between employees inhibit Knowledge } \\
\text { Sharing in organisation. }\end{array}$ & 2.3297 & 0.94388 & Low \\
\hline 6 & $\begin{array}{l}\text { Large differences in education levels between employees inhibit Knowledge Sharing } \\
\text { in the organisation. }\end{array}$ & 2.1868 & 1.04578 & Low \\
\hline 7 & Lack of social networks inhibit Knowledge Sharing in organisation. & 3.7949 & 1.12543 & High \\
\hline 8 & Lack of courage to express oneself act as a barrier to Knowledge Sharing. & 2.1685 & 1.14122 & Low \\
\hline
\end{tabular}

Table 5 indicates the fact that the means of items are greater than the virtual means; 3 indicated that individuals' barriers are considered, whilst conversely, items 5, 6, and 8 have the lowest mean values, reflecting that the differences between employees (e.g., experiences and education) do not prevent KS.

Table 6 details the means of the organisational barriers' items, also indicating the fact that the means of all the items of the organisational barriers are greater than the 4 . There is agreement that the organisational barriers are the main reasons for hindering the sharing of knowledge.

Table 6. Organisational Barriers

\begin{tabular}{|c|c|c|c|c|}
\hline & Question & Mean & SD & Degree \\
\hline 9 & $\begin{array}{l}\text { Lack of moral reward when an employee shares his knowledge } \\
\text { hinders Knowledge Sharing in an organisation. }\end{array}$ & 4.3150 & 0.46538 & Very high \\
\hline 10 & $\begin{array}{c}\text { Hierarchical organisation structure inhibits/slows Knowledge } \\
\text { Sharing within an organisation. }\end{array}$ & 4.3040 & 0.46084 & Very high \\
\hline 11 & $\begin{array}{l}\text { Internal competitiveness within business units and organisations } \\
\text { inhibit Knowledge Sharing within organisations. }\end{array}$ & 4.3553 & 0.47949 & Very high \\
\hline 12 & $\begin{array}{c}\text { Lack of a transparent rewards and recognition systems inhibit } \\
\text { Knowledge Sharing within organisations. }\end{array}$ & 4.2711 & 0.44532 & Very high \\
\hline 13 & $\begin{array}{c}\text { Lack of financial reward when an employee shares his knowledge } \\
\text { hinders Knowledge Sharing in an organisation. }\end{array}$ & 4.4029 & 0.49139 & Very high \\
\hline 14 & $\begin{array}{c}\text { Lack of organisational support hinders Knowledge Sharing in an } \\
\text { organisation. }\end{array}$ & 4.2564 & 0.43745 & Very high \\
\hline 15 & $\begin{array}{l}\text { A high degree of centralisation and formalisation inhibits/slows } \\
\text { Knowledge Sharing within the organisation. }\end{array}$ & 4.4103 & 0.49278 & Very high \\
\hline
\end{tabular}

Table 7 shows the means of technology barriers items, indicating that the technology barriers to KS are 'Average', only one item being 'Low'.

Table 7. Technology Barriers

\begin{tabular}{|c|c|c|c|c|}
\hline & Question & Mean & SD & Degree \\
\hline 16 & $\begin{array}{c}\text { Lack of information technology in organisations inhibit Knowledge } \\
\text { Sharing. }\end{array}$ & 3.3297 & 1.49550 & Average \\
\hline 17 & $\begin{array}{c}\text { Lack of information technology that is easy to use will inhibit Knowledge } \\
\text { Sharing. }\end{array}$ & 3.1502 & 1.32682 & Average \\
\hline 18 & $\begin{array}{l}\text { Lack of sophisticated information technology helping to capture and store } \\
\text { knowledge inhibit Knowledge Sharing within the organisation. }\end{array}$ & 2.5201 & 1.28358 & Low \\
\hline
\end{tabular}

Table 8 presents the means of knowledge nature barriers items, reporting that all the means of these items are below three, being a low degree. 
Table 8. Knowledge Nature Barriers

\begin{tabular}{|c|c|c|c|c|}
\hline & Question & Mean & SD & Degree \\
\hline 19 & It is very difficult to share knowledge that's not explicit. & 2.4103 & 1.21880 & Low \\
\hline 20 & It is very difficult to capture knowledge that's not explicit. & 2.4542 & 1.17523 & Low \\
\hline 21 & $\begin{array}{c}\text { The knowledge with high degrees of tacit are considered to be barrier to } \\
\text { sharing knowledge. }\end{array}$ & 2.2857 & 1.05321 & Low \\
\hline
\end{tabular}

\section{Hypothesis Testing}

- H1-1: There are no statistically significant differences between the responses of the sample members at the level of $\alpha \leq 0.05$ on the barriers to sharing knowledge from the employees within the hospitality industry attributed to the gender variable.

An independent samples t-test was conducted to test this hypothesis, Table 9 demonstrating the founded result, which supports this hypothesis; thus, there are, indeed, no differences between males and females with respect to the barriers to $\mathrm{KS}$ within the hospitality industry.

Table 9. T-test Result (Gender)

\begin{tabular}{|c|c|c|c|c|c|c|c|c|c|c|}
\hline Gender & & $\mathrm{N}$ & Mean & $\begin{array}{c}\text { Std. } \\
\text { Deviation }\end{array}$ & $\begin{array}{c}\text { Std. } \\
\text { Error } \\
\text { Mean }\end{array}$ & $\begin{array}{c}\text { Equal } \\
\text { variances }\end{array}$ & $\begin{array}{c}\text { Sig. } \\
\text { (2-tailed) }\end{array}$ & $\begin{array}{c}\text { Mean } \\
\text { Difference }\end{array}$ & $\mathrm{t}$ & $\mathrm{F}$ \\
\hline Individual & Male & 210 & 2.4018 & 0.76340 & 0.05268 & assumed & 0.228 & 0.12798 & 1.210 & 4.442 \\
\hline Barriers & Female & 63 & 2.2738 & 0.63772 & 0.08034 & $\begin{array}{c}\text { not } \\
\text { assumed }\end{array}$ & 0.185 & 0.12798 & 1.332 & \\
\hline Organisational & Male & 210 & 4.3422 & 0.26666 & 0.01840 & assumed & 0.179 & 0.04966 & 1.347 & 6.627 \\
\hline Barriers & Female & 63 & 4.2925 & 0.21986 & 0.02770 & $\begin{array}{c}\text { not } \\
\text { assumed }\end{array}$ & 0.138 & 0.04966 & 1.493 & \\
\hline Technological & Male & 210 & 2.9762 & 1.05155 & 0.07256 & assumed & 0.490 & -0.10317 & -0.692 & 0.751 \\
\hline Barriers & Female & 63 & 3.0794 & 0.99229 & 0.12502 & $\begin{array}{c}\text { not } \\
\text { assumed }\end{array}$ & 0.477 & -0.10317 & -0.714 & \\
\hline Knowledge & Male & 210 & 2.3683 & 0.90356 & 0.06235 & assumed & 0.608 & -0.06561 & -0.514 & 1.125 \\
\hline Nature Barriers & Female & 63 & 2.4339 & 0.83523 & 0.10523 & $\begin{array}{c}\text { not } \\
\text { assumed }\end{array}$ & 0.593 & -0.06561 & -0.536 & \\
\hline \multirow[t]{2}{*}{ Total } & Male & 210 & 3.4490 & 0.26097 & 0.01801 & assumed & 0.935 & -0.00302 & -0.082 & 1.009 \\
\hline & Female & 63 & 3.4520 & 0.24712 & 0.03113 & $\begin{array}{c}\text { not } \\
\text { assumed }\end{array}$ & 0.933 & -0.00302 & -0.084 & \\
\hline
\end{tabular}

- H2: There are no statistically significant differences between the responses of the sample members at the level of $\alpha \leq 0.05$ on the barriers to sharing knowledge from the employees within the hospitality industry attributed to the job variable.

An independent samples t-test was conducted to test this hypothesis, Table 10 detailing the result, which supports this hypothesis; thus, there are, indeed, no differences between manager and employee concerning the barriers to KS within the hospitality industry.

Table 10. T-test Result (Job)

\begin{tabular}{|c|c|c|c|c|c|c|c|c|c|c|}
\hline Job & & $\mathrm{N}$ & Mean & $\begin{array}{c}\text { Std. } \\
\text { Deviation }\end{array}$ & $\begin{array}{l}\text { Std. } \\
\text { Error } \\
\text { Mean }\end{array}$ & $\begin{array}{c}\text { Equal } \\
\text { variances }\end{array}$ & $\begin{array}{c}\text { Sig. } \\
\text { (2-tailed) }\end{array}$ & $\begin{array}{c}\text { Mean } \\
\text { Difference }\end{array}$ & $\mathrm{t}$ & $\mathrm{F}$ \\
\hline Individual & Manager & 41 & 2.3140 & 0.74221 & 0.11591 & Assumed & 0.584 & -0.06852 & -0.548 & 0.006 \\
\hline Barriers & Employee & 232 & 2.3825 & 0.73741 & 0.04841 & $\begin{array}{c}\text { Not } \\
\text { assumed }\end{array}$ & 0.588 & -0.06852 & -0.545 & \\
\hline Organisational & Manager & 41 & 4.2857 & 0.23690 & 0.03700 & Assumed & 0.225 & -0.05296 & -1.217 & 1.501 \\
\hline Barriers & Employee & 232 & 4.3387 & 0.26016 & 0.01708 & $\begin{array}{c}\text { Not } \\
\text { assumed }\end{array}$ & 0.199 & -0.05296 & -1.300 & \\
\hline Technological & Manager & 41 & 3.0325 & 1.07705 & 0.16821 & Assumed & 0.828 & 0.03827 & 0.217 & 0.012 \\
\hline Barriers & Employee & 232 & 2.9943 & 1.03241 & 0.06778 & $\begin{array}{c}\text { Not } \\
\text { assumed }\end{array}$ & 0.834 & 0.03827 & 0.211 & \\
\hline Knowledge & Manager & 41 & 2.4309 & 0.97822 & 0.15277 & Assumed & 0.711 & 0.05589 & 0.371 & 0.850 \\
\hline Nature Barriers & Employee & 232 & 2.3750 & 0.87215 & 0.05726 & $\begin{array}{c}\text { Not } \\
\text { assumed }\end{array}$ & 0.733 & 0.05589 & 0.343 & \\
\hline \multirow[t]{2}{*}{ Total } & Manager & 41 & 3.4472 & 0.26872 & 0.04197 & Assumed & 0.946 & -0.00297 & -0.068 & 0.092 \\
\hline & Employee & 232 & 3.4501 & 0.25595 & 0.01680 & $\begin{array}{c}\text { Not } \\
\text { assumed }\end{array}$ & 0.948 & -0.00297 & -0.066 & \\
\hline
\end{tabular}

- H4: There are no statistically significant differences between the responses of the sample members at the level of $\alpha \leq 0.05$ on the barriers to sharing knowledge from the employees within the hospitality industry attributed to the years of experience variable. 
The one-way analysis of variance (ANOVA) has been used to test this hypothesis, Table 11 detailing the output of the ANOVA analysis, from which we can see that the significance values are above 0.05 ; this supports this hypothesis and, thus, there are, indeed, no differences concerning the barriers to KS within the hospitality industry concerning the experiences of the sample members.

Table 11. One-way ANOVA Result (Experience)

\begin{tabular}{|c|c|c|c|c|c|c|}
\hline Experience & & Sum of Squares & $\mathrm{df}$ & Mean Square & $\mathrm{F}$ & Sig. \\
\hline \multirow[t]{3}{*}{ Individual Barriers } & Between Groups & 1.056 & 2 & 0.528 & 0.971 & 0.380 \\
\hline & Within Groups & 146.755 & 270 & 0.544 & & \\
\hline & Total & 147.810 & 272 & & & \\
\hline \multirow[t]{3}{*}{ Organisational Barriers } & Between Groups & 0.098 & 2 & 0.049 & 0.743 & 0.477 \\
\hline & Within Groups & 17.879 & 270 & 0.066 & & \\
\hline & Total & 17.978 & 272 & & & \\
\hline \multirow[t]{3}{*}{ Technological Barriers } & Between Groups & 0.002 & 2 & 0.001 & 0.001 & 0.999 \\
\hline & Within Groups & 292.665 & 270 & 1.084 & & \\
\hline & Total & 292.667 & 272 & & & \\
\hline \multirow[t]{3}{*}{ Knowledge Nature Barriers } & Between Groups & 2.655 & 2 & 1.327 & 1.695 & 0.186 \\
\hline & Within Groups & 211.439 & 270 & 0.783 & & \\
\hline & Total & 214.094 & 272 & & & \\
\hline \multirow[t]{3}{*}{ Total } & Between Groups & 0.053 & 2 & 0.027 & 0.399 & 0.671 \\
\hline & Within Groups & 17.968 & 270 & 0.067 & & \\
\hline & Total & 18.021 & 272 & & & \\
\hline
\end{tabular}

- H3: There are no statistically significant differences between the responses of the sample members at the level of $\alpha \leq 0.05$ on the barriers to sharing knowledge from the employees within the hospitality industry attributed to the age variable.

To test the hypothesis, one-way analysis of variance (ANOVA) has been used; Table 12 shows the output of the ANOVA analysis, from which we can see that the significance values are above 0.05 within organisational, technological, and knowledge nature barriers, whilst the significance was below 0.05 for the individual barriers (0.016).

Table 12. One-way ANOVA Result (Age)

\begin{tabular}{|c|c|c|c|c|c|c|}
\hline Age & & Sum of Squares & df & Mean Square & $\mathrm{F}$ & Sig. \\
\hline \multirow[t]{3}{*}{ Individual Barriers } & Between Groups & 4.459 & 2 & 2.230 & 4.200 & 0.016 \\
\hline & Within Groups & 143.351 & 270 & 0.531 & & \\
\hline & Total & 147.810 & 272 & & & \\
\hline \multirow[t]{3}{*}{ Organisational Barriers } & Between Groups & 6.278 & 2 & 3.139 & 2.959 & 0.054 \\
\hline & Within Groups & 286.389 & 270 & 1.061 & & \\
\hline & Total & 292.667 & 272 & & & \\
\hline \multirow[t]{3}{*}{ Technological Barriers } & Between Groups & 0.082 & 2 & 0.041 & 0.620 & 0.539 \\
\hline & Within Groups & 17.896 & 270 & 0.066 & & \\
\hline & Total & 17.978 & 272 & & & \\
\hline \multirow[t]{3}{*}{ Knowledge Nature Barriers } & Between Groups & 0.060 & 2 & 0.030 & 0.038 & 0.963 \\
\hline & Within Groups & 214.034 & 270 & 0.793 & & \\
\hline & Total & 214.094 & 272 & & & \\
\hline \multirow[t]{3}{*}{ Total } & Between Groups & 0.093 & 2 & 0.046 & 0.699 & 0.498 \\
\hline & Within Groups & 17.928 & 270 & 0.066 & & \\
\hline & Total & 18.021 & 272 & & & \\
\hline
\end{tabular}

Moreover, a Scheffe post hoc test revealed that the difference was between age (20-29) and (30-39) in favour of age (30-39) (see Table 13).

Table 13. Scheffe Result

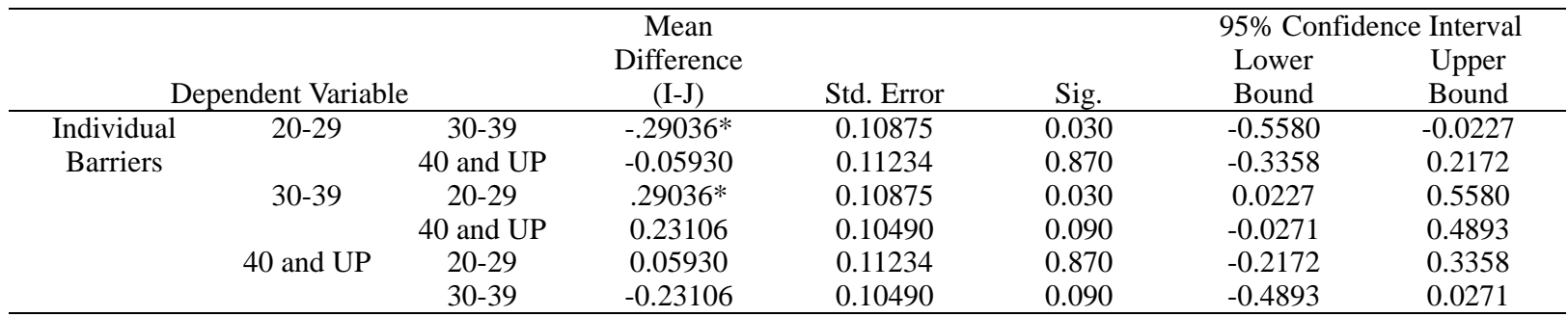

- H5: There are no statistically significant differences between the responses of the sample members at the level of $\alpha \leq 0.05$ on the barriers to sharing knowledge from the employees within the hospitality industry attributed to the qualifications variable. 
The one-way analysis of variance (ANOVA) has been used to test this hypothesis; Table 14 details the output of the ANOVA analysis, and from it we can see that the significance values are above 0.05 , thus supporting this hypothesis. Therefore, there are no differences concerning the barriers to KS within the hospitality industry concerning the qualifications of sample members.

Table 14. One-way ANOVA Result (Qualification)

\begin{tabular}{|c|c|c|c|c|c|c|}
\hline Qualification & & Sum of Squares & $\mathrm{df}$ & Mean Square & $\mathrm{F}$ & Sig. \\
\hline \multirow[t]{3}{*}{ Individual Barriers } & Between Groups & 0.139 & 2 & 0.070 & 0.268 & 0.765 \\
\hline & Within Groups & 70.267 & 270 & 0.260 & & \\
\hline & Total & 70.406 & 272 & & & \\
\hline \multirow[t]{3}{*}{ Organisational Barriers } & Between Groups & 2.704 & 2 & 1.352 & 2.998 & 0.052 \\
\hline & Within Groups & 121.755 & 270 & 0.451 & & \\
\hline & Total & 124.459 & 272 & & & \\
\hline \multirow[t]{3}{*}{ Technological Barriers } & Between Groups & 0.775 & 2 & 0.387 & 1.883 & 0.154 \\
\hline & Within Groups & 55.551 & 270 & 0.206 & & \\
\hline & Total & 56.326 & 272 & & & \\
\hline \multirow[t]{3}{*}{ Knowledge Nature Barriers } & Between Groups & 0.388 & 2 & 0.194 & 0.445 & 0.641 \\
\hline & Within Groups & 117.662 & 270 & 0.436 & & \\
\hline & Total & 118.050 & 272 & & & \\
\hline \multirow{3}{*}{ Total } & Between Groups & 0.644 & 2 & 0.322 & 1.334 & 0.265 \\
\hline & Within Groups & 65.120 & 270 & 0.241 & & \\
\hline & Total & 65.764 & 272 & & & \\
\hline
\end{tabular}

\section{Discussion and Conclusion}

This investigation developed a tool based on an extensive literature review for measuring barriers to KS considering this research primarily aimed to investigate and identify the main barriers in KS within the Jordanian hospitality industry; moreover, barriers to KS were measured by four components, including individual barriers, organisational barriers, technology barriers, and knowledge nature barriers.

These findings correlate with several previous studies that have considered barriers to KS (e.g., individuals and organisational barriers) (e.g., Szulanski, 1996; Riege, 2005; Kukko, 2013); further, the empirical findings of this research correlate with KS literature, which has shed light on the significant impact of the nature of knowledge on the success of KS. For instance, Ipe (2003) proposed that the nature of both tacit and explicit knowledge forms a significant factor influencing KS between employees within the organisation.

Notably, the findings of this research match with those of Amayah (2013), who indicated that the organisational structure impacted KS within the public sector; it was within this study that the organisation's structural characteristics (formalisation and centralisation) were also deemed to be significant barriers to KS. Our findings additionally correlate with those of Lin (2008), who discovered that there are three factors impacting KS amongst organisation units: organisational structure characteristics, organisational culture, and interunit interaction.

Prior studies have suggested that low awareness of the value of possessed knowledge comprises one of the main barriers for KS within the organisation (e.g., Riege, 2005; Kukko, 2013).

These findings agree with many previously conducted studies, which have considered the lack of time to be a barrier for KS, whether collecting or donating knowledge (e.g. Szulanski, 1996; Riege, 2005; Kukko, 2013).

These findings provide additional support for any past studies that have proposed a reward system for encouraging employees to share their knowledge (e.g., Bartol \& Srivastava, 2002; Ipe, 2003; Cabrera, Collins, \& Salgado, 2006; Al-Alawi et al., 2007; Lin, Hung ,\& Chen, 2009); meanwhile, these findings are additionally in line with various prior studies that have considered lack of organisational rewards to be barriers impeding employees when it comes to contributing their organisational knowledge (e.g., Riege, 2005; Lee \& Ahn, 2007; Sandhu et al., 2011 ).

These results signify that there are generally no statistically significant differences between the responses of the sample members at the level of $\alpha \leq 0.05$ on the barriers to sharing knowledge from the employees within the hospitality industry attributed to the variables gender, job, age, years of experience, qualifications.

The findings of this study propose several practical contributions to the Jordanian hospitality industry in terms of what factors act as main barriers to KS within such industries; the findings of this study additionally provide a roadmap for the Jordanian hospitality industry to overcome such barriers via understanding the main source of these barriers. 


\section{Limitation and Future Researches}

The main limitation of this study concerns the generalisability of these results. This study was conducted in Jordan as a rich developing country context and in particular in the hospitality industry as a type of service organisation. Although this context might undermine the generalisability of this research, it allowed for controlling for cultural and industrial differences in the analysis. Therefore, conducting future research in other service organisations or public organisations in Jordan or other countries might lead to a more comprehensive understanding of the phenomenon KS.

\section{References}

$\mathrm{Al}$ Hawamdeh, N. (2018). An Investigation of the role of knowledge brokers during service encounters: the context of Jordanian commercial banks (Doctoral dissertation, Brunel University London).

Al Hawamdeh, N., \& Hackney, R. A. (2018). An investigation of knowledge brokering during service encounters. Online Journal of Applied Knowledge Management (OJAKM), 6(1), 187-210.

Al-Alawi, A., Al-Marzooqi, N., \& Mohammed, Y. (2007). Organizational culture and knowledge sharing: critical success factors. Journal of Knowledge Management, 11(2), 22-42. https://doi.org/10.1108/13673270710738898

Alavi, M., \& Leidner, D. E. (2001). Knowledge management and knowledge management systems: Conceptual foundations and research issues. MIS Quarterly, 107-136. https://doi.org/10.2307/3250961

Al-Hawamdeh, S. (2003). Knowledge management: cultivating knowledge professionals. Elsevier. https://doi.org/10.1533/9781780631936

Amayah, A. (2013). Determinants of knowledge sharing in a public sector organization. Journal of Knowledge Management, 17(3), 454-471. https://doi.org/10.1108/JKM-11-2012-0369

Bartol, K. M., \& Srivastava, A. (2002). Encouraging knowledge sharing: The role of organizational reward systems. Journal of Leadership \& Organizational Studies, 9(1), 64-76. https://doi.org/10.1177/107179190200900105

Bloice, L., \& Burnett, S. (2016). Barriers to knowledge sharing in third sector social care: a case study. Journal of Knowledge Management, 20(1), 125-145. https://doi.org/10.1108/JKM-12-2014-0495

Busch, P. (Ed.). (2008). Tacit knowledge in organizational learning. Igi Global. https://doi.org/10.4018/978-1-59904-501-6

Cabrera, A., Collins, W. C., \& Salgado, J. F. (2006). Determinants of individual engagement in knowledge sharing. The International Journal of Human Resource Management, 17(2), 245-264. https://doi.org/10.1080/09585190500404614

Calantone, R. J., Cavusgil, S. T., \& Zhao, Y. (2002). Learning orientation, firm innovation capability, and firm performance. Industrial marketing management, 31(6), 515-524. https://doi.org/10.1016/S0019-8501(01)00203-6

Chen, C. J., \& Huang, J. W. (2007). How organizational climate and structure affect knowledge management-The social interaction perspective. International journal of information management, 27(2), 104-118. https://doi.org/10.1016/j.ijinfomgt.2006.11.001

Chow, W. S., \& Chan, L. S. (2008). Social network, social trust and shared goals in organizational knowledge sharing. Information \& management, 45(7), 458-465. https://doi.org/10.1016/j.im.2008.06.007

Chumg, H. F., Cooke, L., Fry, J., \& Hung, I. H. (2015). Factors affecting knowledge sharing in the virtual organisation: Employees' sense of well-being as a mediating effect. Computers in Human Behavior, 44, 70-80. https://doi.org/10.1016/j.chb.2014.11.040

Creswell, J. W., \& Creswell, J. D. (2017). Research design: Qualitative, quantitative, and mixed methods approaches. Sage publications.

Davenport, T. H., \& Prusak, L. (1998). Working knowledge: How organizations manage what they know. Harvard Business Press.

De Long, D. W., \& Fahey, L. (2000). Diagnosing cultural barriers to knowledge management. Academy of Management Perspectives, 14(4), 113-127. https://doi.org/10.5465/ame.2000.3979820

Dinçer, M. Z., \& Alrawadieh, Z. (2017). Negative word of mouse in the hotel industry: A content analysis of online reviews on luxury hotels in Jordan. Journal of Hospitality Marketing \& Management, 26(8), 785-804. https://doi.org/10.1080/19368623.2017.1320258 
Disterer, G. (2001, January). Individual and social barriers to knowledge transfer. In Proceedings of the 34th annual Hawaii international conference on system sciences (pp. 7-pp). IEEE.

Fey, C. F., \& Furu, P. (2008). Top management incentive compensation and knowledge sharing in multinational corporations. Strategic Management Journal, 29(12), 1301-1323. https://doi.org/10.1002/smj.712

Ford, D., Myrden, S. E., \& Jones, T. D. (2015). Understanding "disengagement from knowledge sharing": engagement theory versus adaptive cost theory. Journal of Knowledge Management, 19(3), 476-496. https://doi.org/10.1108/JKM-11-2014-0469

Goh, S. C. (2002). Managing effective knowledge transfer: an integrative framework and some practice implications. Journal of Knowledge Management, 6(1), 23-30. https://doi.org/10.1108/13673270210417664

Hau, Y. S., Kim, B., Lee, H., \& Kim, Y. G. (2013). The effects of individual motivations and social capital on employees' tacit and explicit knowledge sharing intentions. International Journal of Information Management, 33(2), 356-366. https://doi.org/10.1016/j.ijinfomgt.2012.10.009

Hawryszkiewycz, I. (2009). Knowledge management: organizing knowledge based enterprises. Macmillan International Higher Education.

Hendriks, P. (1999). Why share knowledge? The influence of ICT on the motivation for knowledge sharing. Knowledge and process management, 6(2), 91-100. https://doi.org/10.1002/(SICI)1099-1441(199906)6:2<91::AID-KPM54>3.0.CO;2-M

Hu, M. L. M., Horng, J. S., \& Sun, Y. H. C. (2009). Hospitality teams: Knowledge sharing and service innovation performance. Tourism management, 30(1), 41-50. https://doi.org/10.1016/j.tourman.2008.04.009

Ipe, M. (2003). Knowledge sharing in organizations: A conceptual framework. Human resource development review, 2(4), 337-359. https://doi.org/10.1177/1534484303257985

Kim, S., \& Lee, H. (2006). The impact of organizational context and information technology on employee knowledge-sharing capabilities. Public Administration Review, 66(3), 370-385. https://doi.org/10.1111/j.1540-6210.2006.00595.x

Kim, S., Suh, E., \& Jun, Y. (2011). Building a Knowledge Brokering System using social network analysis: A case study of the Korean financial industry. Expert systems with applications, 38(12), 14633-14649. https://doi.org/10.1016/j.eswa.2011.05.019

Kivrak, S., Arslan, G., Tuncan, M., \& Birgonul, M. T. (2014). Impact of national culture on knowledge sharing in international construction projects. Canadian Journal of Civil Engineering, 41(7), 642-649. https://doi.org/10.1139/cjce-2013-0408

Kukko, M. (2013). Knowledge sharing barriers in organic growth: A case study from a software company. The Journal of High Technology Management Research, 24(1), 18-29. https://doi.org/10.1016/j.hitech.2013.02.006

Lee, D. J., \& Ahn, J. H. (2007). Reward systems for intra-organizational knowledge sharing. European Journal of Operational Research, 180(2), 938-956. https://doi.org/10.1016/j.ejor.2006.03.052

Lin, H. F. (2007). Effects of extrinsic and intrinsic motivation on employee knowledge sharing intentions. Journal of information science, 33(2), 135-149. https://doi.org/10.1177/0165551506068174

Lin, M. J. J., Hung, S. W., \& Chen, C. J. (2009). Fostering the determinants of knowledge sharing in professional virtual communities. Computers in Human Behavior, 25(4), 929-939. https://doi.org/10.1016/j.chb.2009.03.008

Lin, W. B. (2008). The effect of knowledge sharing model. Expert systems with applications, 34(2), 1508-1521. https://doi.org/10.1016/j.eswa.2007.01.015

Nonaka, I. \& Toyama, R. (2005). The Theory of the Knowledge-creating Firm: Subjectivity, objectivity and synthesis. Industrial and Corporate Change, 14(3), 419-436. https://doi.org/10.1093/icc/dth058

Nonaka, I. (1994). A dynamic theory of organizational knowledge creation. Organization science, 5(1), 14-37. https://doi.org/10.1287/orsc.5.1.14

Nonaka, I., \& Takeuchi, H. (1995). The Knowledge Creating. New York, 304.

Nonaka, I., Toyama, R., \& Konno, N. (2000). SECI, Ba and leadership: a unified model of dynamic knowledge creation. Long Range Planning, 33(1), 5-34. https://doi.org/10.1016/S0024-6301(99)00115-6

Pan, Y., Xu, Y. C., Wang, X., Zhang, C., Ling, H. \& Lin, J. (2015) Integrating social networking support for dyadic knowledge exchange: A study in a virtual community of practice, Information \& Management, 52(1), 61-70. https://doi.org/10.1016/j.im.2014.10.001 
Polanyi, M. (2009). The tacit dimension. University of Chicago press.

Razmerita, L., Kirchner, K., \& Nielsen, P. (2016). What factors influence knowledge sharing in organizations? A social dilemma perspective of social media communication. Journal of Knowledge Management, 20(6), 1225-1246. https://doi.org/10.1108/JKM-03-2016-0112

Riege, A. (2005). Three-dozen knowledge-sharing barriers managers must consider. Journal of knowledge management, 9(3), 18-35. https://doi.org/10.1108/13673270510602746

Sandhu, M., Jain, K., \& Ahmad, I. (2011). Knowledge sharing among public sector employees: evidence from Malaysia. International Journal of Public Sector Management, 24(3), 206-226. https://doi.org/10.1108/09513551111121347

Saunders, M., Lewis, P., \& Thornhill, A. (2009). Research methods for business students. Essex. Financial Times/Prentice Hall.

Seba, I., \& Rowley, J. (2010). Knowledge management in UK police forces. Journal of Knowledge Management, 14(4), 611-626. https://doi.org/10.1108/13673271011059554

Seba, I., Rowley, J., \& Delbridge, R. (2012). Knowledge sharing in the Dubai police force. Journal of Knowledge Management, 16(1), 114-128. https://doi.org/10.1108/13673271211198972

Small, C. T., \& Sage, A. P. (2005). Knowledge management and knowledge sharing: A review. Information Knowledge systems management, 5(3), 153-169.

Staples, D. S., \& Webster, J. (2008). Exploring the effects of trust, task interdependence and virtualness on knowledge sharing in teams. Information Systems Journal, 18(6), 617-640. https://doi.org/10.1111/j.1365-2575.2007.00244.x

Swan, J., Newell, S., Scarbrough, H., \& Hislop, D. (1999). Knowledge management and innovation: networks and networking. Journal of Knowledge Management, 3(4), 262-275. https://doi.org/10.1108/13673279910304014

Szulanski, G. (1996). Exploring internal stickiness: Impediments to the transfer of best practice within the firm. Strategic management journal, 17(S2), 27-43. https://doi.org/10.1002/smj.4250171105

Taylor, W. A., \& Wright, G. H. (2004). Organizational readiness for successful knowledge sharing: Challenges for public sector managers. Information Resources Management Journal (IRMJ), 17(2), 22-37. https://doi.org/10.4018/irmj.2004040102

Van den Hooff, B., \& Huysman, M. (2009). Managing knowledge sharing: Emergent and engineering approaches. Information \& management, 46(1), 1-8. https://doi.org/10.1016/j.im.2008.09.002

Wang, M. L. (2015). Learning climate and customer-oriented behaviors: the mediation of customer knowledge. Journal of Managerial Psychology, 30(8), 955-969. https://doi.org/10.1108/JMP-09-2013-0310

Wang, S., \& Noe, R. A. (2010). Knowledge sharing: A review and directions for future research. Human resource management review, 20(2), 115-131. https://doi.org/10.1016/j.hrmr.2009.10.001

Wei, J., Stankosky, M., Calabrese, F., \& Lu, L. (2008). A framework for studying the impact of national culture on knowledge sharing motivation in virtual teams. Vine, 38(2), 221-231. https://doi.org/10.1108/03055720810889851

Wiig, K. M. (1997). Knowledge management: where did it come from and where will it go? Expert systems with applications, 13(1), 1-14. https://doi.org/10.1016/S0957-4174(97)00018-3

Yang, H. L., \& Wu, T. C. (2008). Knowledge sharing in an organization. Technological Forecasting and Social Change, 75(8), 1128-1156. https://doi.org/10.1016/j.techfore.2007.11.008

Yang, S. C., \& Farn, C. K. (2009). Social capital, behavioural control, and tacit knowledge sharing-A multi-informant design. International Journal of Information Management, 29(3), 210-218. https://doi.org/10.1016/j.ijinfomgt.2008.09.002

Zhang, X., De Pablos, P. O., \& Xu, Q. (2014). Culture effects on the knowledge sharing in multi-national virtual classes: A mixed method. Computers in Human Behavior, 31, 491-498. https://doi.org/10.1016/j.chb.2013.04.021

\section{Copyrights}

Copyright for this article is retained by the author(s), with first publication rights granted to the journal.

This is an open-access article distributed under the terms and conditions of the Creative Commons Attribution license (http://creativecommons.org/licenses/by/4.0/). 